\title{
MOVIMENTAÇÃO E DIETA DURANTE O TRABALHO DE PARTO: A PERCEPÇÃO DE UM GRUPO DE PUERPÉRAS ${ }^{1}$
}

\author{
Chang Yi Wei², Dulce Maria Rosa Gualda ${ }^{3}$, Hudson Pires de Oliveira Santos Junior ${ }^{4}$
}

\footnotetext{
${ }^{1}$ Trata-se de um recorte da dissertação - Ações humanizadoras na assistência ao parto: experiência e percepções de um grupo de mulheres em um hospital-escola, apresentada ao Programa de Pós-Graduação em Enfermagem da Universidade de São Paulo (USP), em 2008.

${ }^{2}$ Mestre em Enfermagem. Chefe da seção de enfermagem do Centro Obstétrico do Hospital Universitário da USP. São Paulo, Brasil. E-mail: changwei@hu.usp.br

${ }^{3}$ Doutora em Enfermagem. Professora Titular do Departamento de Enfermagem Materno-infantil e Psiquiátrica da Escola de Enfermagem (EE) da USP. São Paulo, Brasil E-mail: drgualda@usp.br

${ }^{4}$ Doutorando em Enfermagem no Programa Interunidades de Doutoramento da EE-EERP/USP. Bolsista FAPESP. São Paulo, Brasil. E-mail: hudsonjr@usp.br
}

\begin{abstract}
RESUMO: Este estudo teve como objetivo conhecer a experiência e a percepção de um grupo de mulheres em relação à deambulação e à dieta durante o trabalho de parto. Pesquisa qualitativa descritiva, realizada em hospital de ensino de São Paulo. Os dados foram coletados por meio de entrevista com 35 mulheres que tiveram filhos de parto vaginal, em dois momentos dinstintos, no referido hospital. Os resultados apontam que, para algumas mulheres, a deambulação contribui no alívio da dor e na progressão do parto, enquanto que para outras há insegurança para fazer força, devido ao medo de o bebê cair no chão. Quanto à dieta, as mulheres que se alimentaram, relataram sentir mais força durante o parto, e as que não quiseram receber dieta, justificaram medo de atrapalhar no parto. Conclui-se que é crucial levar em consideração a individualidade e a autonomia de escolha das mulheres; premissas básicas quando se busca a assistência humanizada.
\end{abstract}

DESCRITORES: Parto humanizado. Humanização da sssistência. Enfermagem obstétrica.

\section{WALKING AND DIET DURING LABOR: PERCEPTIONS FROM A GROUP OF POSTPARTUM WOMEN}

\begin{abstract}
The objective of this study was to better understand the experience and perceptions of a group of women with respect to walking and diet during labor. This is a qualitative, descriptive study, performed in a teaching hospital in São Paulo, Brazil. Data was collected through interviewing a sample of 35 women who had vaginal deliveries at two different moments in that hospital. The results show that walking helps some of these women to relieve pain and contributed to their labor progression, while others felt insecurity forcing themselves during delivery, due to fear of the baby falling to the floor. With respect to diet, the women who ate reported feeling stronger during childbirth, and those who declined food justified it through their fear of disturbing labor. One concludes that it is crucial to take into consideration the individuality and autonomy of the woman's choice; basic premises when seeking humanized care.

DESCRIPTORS: Humanizing delivery. Humanization of assistance. Obstetrical nursing.
\end{abstract}

\section{CAMINADA Y DIETA DURANTE EL PARTO: LA PERCEPCIÓN DE UN GRUPO DE PUÉRPERAS}

\begin{abstract}
RESUMEN: Este estudio intenta comprender la experiencia y percepción de un grupo de mujeres en relación a caminar y a la dieta durante el parto. Este es un estudio cualitativo descriptivo realizado en un hospital universitario en Sao Paulo. La recolección de datos se hizo mediante entrevistas a treinta y cinco mujeres que dieron a luz por vía vaginal en dos momentos diferentes en el mismo hospital. Los resultados muestran que para algunas mujeres caminar ayuda a aliviar el dolor y la progresión del trabajo del parto, mientras que para otras hay inseguridad para hacer fuerza, debido al temor de que el bebé se caiga al piso. En relación a la dieta, las mujeres que se alimentaron, manifestaron sentirse más fuertes durante el parto y las que no la aceptaron, lo justifican por el temor de perjudicar el parto. Se concluye que es crucial tener en cuenta la individualidad y la autonomía de elección de las mujeres, los supuestos básicos en la búsqueda de una atención humanizada.
\end{abstract}

DESCRIPTORES: Humanización del parto. Humanización de la assistencia. Enfermería obstétrica. 


\section{INTRODUÇÃO}

A Organização Mundial de Saúde (OMS) vem estimulando iniciativas que favoreçam mudanças no atendimento à mulher no ciclo gravídico-puerperal. Dentre elas está a implantação de uma proposta de atendimento mais humanizado ao parto nos serviços de saúde.

No documento "Assistência ao parto normal: um guia prático" ${ }^{1}$, a OMS apresenta um conjunto de práticas que visam à promoção do parto e do nascimento saudáveis e à prevenção da mortalidade materna e perinatal. Tais práticas incluem o respeito ao processo fisiológico e à dinâmica de nascimento, nos quais as intervenções devem ser cuidadosas, evitando-se os excessos e utilizando-se criteriosamente os recursos tecnológicos disponíveis. O guia defende, ainda, como objetivo da assistência obstétrica, o menor nível possível de intervenção, compatível com a segurança, definindo o papel do prestador de serviço como requisito necessário para a concretização deste objetivo. Neste guia, as práticas assistenciais estão categorizadas em quatro grupos.

Categoria A: práticas claramente úteis e que devem ser encorajadas. Estas implicam no reconhecimento da mulher e da família como protagonistas do processo de nascimento, portanto, com poder de decisão.

Categoria B: práticas que são consideradas prejudiciais ou ineficazes e que devem ser abandonadas, pois visam a aceleração do parto em prol do conforto do profissional.

Categoria C: práticas que são utilizadas, porém necessitam ser melhoradas, devendo, por isso, ser adotadas com cautela, pois ainda não possuem fundamento científico consistente e, na maior parte, não levam em consideração a decisão das mulheres em acatá-las ou não.

Categoria D: práticas frequentemente utilizadas, porém inapropriadas, causando mais dano que benefício. Englobam, principalmente, os procedimentos cirúrgicos, incluindo os partos cesáreos e por fórcipes, sem indicação criteriosa para a sua realização.

Dentre os itens que compõem cada categoria, destacamos como objeto de estudo neste artigo, os seguintes tópicos: 1 - Permitir a liberdade de posição e movimento no trabalho de parto (categoria A, item 15); e 2 - Restrição de comida e líquido, durante o trabalho de parto (categoria $\mathrm{D}$, item 1 ).

A razão para esta escolha se deve à necessidade de refletir sobre esses tipos de práticas na perspectiva das pacientes, ampliando, assim, a compreensão dos profissionais sobre o processo assistêncial, de forma a contribuir para a amenização de barreiras na implementação de uma assistência científica e humanisticamente adequa$\mathrm{da}$, que esteja em conformidade com a medicina baseada em evidências, ${ }^{2}$ de forma que as decisões no atendimento ao indivíduo sejam tomadas perante o uso criterioso, consciente e explícito das práticas assistenciais.

No que concerne à liberdade de posição e movimento no trabalho de parto (categoria A, item 15), um estudo experimental mostrou que mulheres capazes de se mover livremente, durante o trabalho de parto, reportaram a movimentação como meio para encontrar um posição confortável. $^{3-4}$ Outra pesquisa aponta que mulheres que foram incentivadas a ficar em pé, caminhar ou se sentar tiveram, em média, trabalhos de partos mais curtos do que mulheres que permaneceram deitadas. ${ }^{5}$

Contudo, criou-se nos hospitais um ritual para o acompanhamento das parturientes, por meio de aparelhos cada vez mais sofisticados, resultando na restrição das parturientes ao leito, a fim de acompanhar cada variação dos batimentos cardiofetais. Como consequência, a restrição na movimentação das parturientes se tornou uma prática inserida no universo cultural dos profissionais, gerando inseguranças quanto à adequada evolução do trabalho de parto e ao bem-estar do feto, caso esse não esteja sendo constantemente monitorado.

Outro ponto a ser explorado é a restrição de comida e líquido, durante o trabalho de parto (categoria D, item 1). Para as mulheres que estão na fase inicial do trabalho de parto e desejam comer, o jejum obrigatório pode causar uma progressão insatisfatória, recaindo na cascata de intervenções que culminam em uma cesariana. ${ }^{6}$ Durante o processo de parturição, o dispêndio de energia é o equivalente ao exercício físico moderado contínuo e, no caso do trabalho de parto prolongado associado ao jejum, há o aumento progressivo de cetonas urinárias. Essa preocupação excessiva dos profissionais com a restrição alimentar deve-se ao risco de aspiração do conteúdo gástrico, caso a parturiente venha a regurgitar durante um procedimento anestésico; porém, evidências apontam que o risco de aspiração está diretamente associado ao uso de anestesia geral no parto, que atualmente é muito baixo, além dos cuidados do profissional que administra a anestesia. ${ }^{5}$ 
Assim, a necessidade de estudos que avaliem práticas obstétricas emergem, devido à medicalização da assistência, que criou um cenário de uso indiscriminável de intervenções, que contribuem para o impacto negativo sobre a morbimortalidade materna, desde meados do século XX. ${ }^{7}$

Considerando fatores que podem contribuir para melhoria da prática assistencial e para o bem-estar maternofetal, este estudo tem como objetivo conhecer a experiência e a percepção de um grupo de mulheres em relação à deambulação e à ingestão de alimentos e líquidos durante o trabalho de parto. Trata-se de um recorte da dissertação de mestrado, que teve como objetivo geral conhecer a experiência e a percepção de parturientes - atendidas em dois eventos de parto distintos, sendo um antes e outro após a implantação de ações humanizadoras em um hospital de ensino - sobre as práticas obstétricas. ${ }^{8}$

\section{METODOLOGIA}

Optou-se por um estudo exploratório, descritivo, com análise qualitativa, pela possibilidade de se captar a maneira pela qual as pessoas pensam e reagem frente às questões focalizadas e de se conhecer a dinâmica e a estrutura da situação do estudo, sob o ponto de vista de quem o vivencia. ${ }^{9}$

O estudo foi desenvolvido no Alojamento Conjunto (AC) do Hospital Universitário da Universidade de São Paulo (HU/USP), localizado no campus universitário de São Paulo. Este hospital está inserido no Sistema Único de Saúde (SUS), sendo a instituição de referência para as unidades básicas de saúde pertencentes à Coordenadoria de Saúde da Subprefeitura do Butantã, região oeste no município de São Paulo, com cerca de 450.000 mil habitantes. Além dessa clientela, são também atendidos discentes, docentes e servidores da universidade, assim como seus dependentes. Em relação à parturição, a média é de 320 partos mensais, sendo cerca de $70 \%$ de partos vaginais e $30 \%$ de partos cesáreas.

Como critério de inclusão das participantes, estabeleceu-se: mulheres que tiveram seus filhos de parto vaginal no HU/USP, em dois momentos dinstintos: anterior ao ano de 2001 (ocasião em que as ações humanizadoras ao parto não estavam totalmente implementadas na instituição) e entre 2006 e 2007, período que as medidas já estavam sendo adotadas.

Para compor o grupo de participantes, os pesquisadores, primeiramente, consultaram a relação de mulheres internadas na maternidade, que haviam tido partos vaginais. Revisando os prontuários, verificou-se se essas mulheres também haviam tido parto vaginal no HU/USP, em período anterior a 2001, sendo esse dado também confirmado pessoalmente com as puérperas. Assim, a amostra do estudo foi constituída por 35 mulheres, sendo estas identificadas de E1 a E35, no corpo do trabalho, garantindo o anonimato.

Os dados foram coletados por meio de entrevistas, através de um roteiro com as questões norteadoras e com espaço para a identificação da participante.

A análise das 35 entrevistas realizadas e transcritas foi efetuada após exaustiva leitura dos seus conteúdos, depois da edição das narrativas, com a supressão de vícios de linguagem e de ideias repetidas, preservando as diferenças individuais de expressão. Após releituras do conteúdo das entrevistas, foram agrupados os relatos de cada entrevistada e realizado o agrupamento dos temas, quando se conseguiu estabelecer com maior clareza as percepções e as categorias emergentes de cada item, pela similaridade dos discursos. Esse processo de análise foi realizado por um dos pesquisadores e, então, comparado com a análise dos demais pesquisadores, de forma a validar os achados.

Em decorrência desse processo, foram identificados os seguintes temas: percepção sobre a experiência de ter feito enema; sobre a possibilidade de deambulação; sobre a oferta de líquidos e alimentos; e sobre a necessidade de tricotomia e episiotomia. A ênfase nas questões da deambulação e da alimentação e ingestão de líquidos emergiu como forte influência no processo de humanização do trabalho de parto para as mulheres, razão pela qual está sendo abordada neste artigo.

O projeto desta pesquisa foi aprovado pelo Comitê de Ética em Pesquisa e Câmara de Ensino e Pesquisa do HU/USP sob n ${ }^{\circ} 639 / 06$, estando em conformidade com as normas da Resolução 196/96 e da Declaração de Helsinki.

\section{RESULTADOS}

\section{Caracterização das participantes}

A idade das colaboradoras deste estudo variou de 22 a 41 anos. O grau de instrução predominante foi o ensino fundamental incompleto, sendo São Paulo a unidade da federação preponderante enquanto origem das participantes. Quanto ao estado civil, a maior parte respondeu que convive 
em união consensual. No que se refere à ocupação, apenas 21 entrevistadas exerciam atividades remuneradas. Quanto à paridade, incluindo $o$ parto atual, para 10 participantes era a sua segunda experiência de parto; para 17 mulheres, a terceira; e era acima do quarto parto para oito entrevistadas. Quanto à realização do pré-natal na gestação atual, mais da metade das mulheres realizou de seis a 10 consultas.

A seguir, estão descritas as categorias temáticas referentes à deambulação e à alimentação e ingestão de líquidos durante o trabalho de parto.

\section{Deambulação durante o trabalho de parto}

Nesta pesquisa, em relação à movimentação durante o trabalho de parto, foram encontradas duas percepções entre as mulheres: mais da metade das entrevistadas referiu que a movimentação e a deambulação são benéficas durante o trabalho de parto, enquanto as outras relataram que preferiam ficar deitadas.

O primeiro grupo aponta que a movimentação proporciona o alívio da dor, possibilita ir ao chuveiro para o banho de ducha e acelera o trabalho de parto. Já o segundo grupo, relaciona a preferência por permanecer deitada, devido ao risco de o bebê nascer durante a movimentação e à dificuldade para fazer força na posição vertical.

No primeiro grupo, a liberdade para deambular foi referida pelas mulheres como importante para suportar e aliviar as dores do trabalho de parto, uma vez que retira o foco de atenção da mulher na dor. Citam que é preferível andar ao permanecer deitada.

[...] fiquei me movimentando bastante, porque parece que alivia a dor. Melhor andar! Ficar deitada parece que a dor aumenta, não sei. Pra mim, melhora se andar. Eu fiquei andando em volta da cama, perto do banheiro, parece que alivia um pouco a dor [...] [parto atual] (E20).

A possibilidade da livre movimentação, associada ao banho, foi citada como outra alternativa para aliviar a sensação de dor e como meio para acelerar o trabalho de parto. Outro aspecto citado foi o fato de o banho distrair e relaxar, minimizando a impaciência da mulher naquele momento.

[...] eu acho que, às vezes, a gente está tão impaciente, que se levantar da cama um pouco, tomar um banho, é melhor que ficar só na cama sentindo a dor. Eu andei, tomei banho, sentei, levantei, porque eu cheguei de madrugada e fui ganhar menino cinco horas da tarde [...] [parto atual] (E9).
[...] além de andar, o banho também alivia bastante, nossa! Desta vez, eu ganhei rapidinho, porque eu tomei banho e fiquei mais calma; aquela água quente na barriga, ai, graças a Deus, foi tudo rapidinho, por causa do banho demorado [...] [parto atual] (E5).

O incentivo, por parte da equipe de saúde, para o banho, foi percebido como uma experiência positiva. $\mathrm{O}$ outro aspecto foi o reconhecimento da reforma do Centro Obstétrico, percebida positivamente, pela adequação do banheiro com a instalação de barras de apoio e cadeira, que deram melhores condições para que as mulheres pudessem relaxar durante o banho.

[...] o pessoal que trabalha lá deu atenção, falava pra ficar jogando água na barriga, que nasce mais rápido, eu, naquela loucura de ver nascer logo. O banho relaxa bastante, tem a cadeirinha que a gente pode estar sentando... não tinha... eu fiquei um pouco e aí já começou a doer [...] [parto atual] (E29).

Comparando-se com a experiência do parto anterior, houve uma percepção de progressão mais rápida, além de alívio da dor. A rápida dilatação do colo uterino foi atribuída à movimentação. O incentivo da equipe para a deambulação foi percebido como importante para a evolução do trabalho de parto.

[...] eu estava com um dedo de dilatação e uma enfermeira me aconselhou a ficar andando, eu andei do meio-dia à 1 h30 e consegui ficar com quatro dedos de dilatação. Adianta o parto andar, que você consegue obter a dilatação, quando você está andando e vem a contração, você pára, respira, pra poder continuar [...] [parto atual] (E23).

[...] vou falar da minha parte, andar me ajudou porque fiquei um tempão estacionada com quatro de dilatação, quando o médico deixou andar uns 40 minutos, fui pra seis, sete dedos, até o médico percebeu que andar ajudou [...] [parto anterior] (E6).

A prática da movimentação antes de se internar no hospital foi citada, pelas mulheres, como uma forma de chegar à instituição em uma fase mais avançada do trabalho de parto.

[...] quando começam as contrações, eu fico em casa esperando, fico me movimentando. Eu acho que o movimentar ajuda sim, porque, aí na hora que vem aqui, já está mais adiantado. Eu acho que se mexer em casa ajuda no trabalho de parto [...] [parto atual] (E25).

A possibilidade de poder se movimentar foi percebida como uma mudança positiva, pois, nos partos anteriores, havia a prática da monitorização contínua dos batimentos cardiofetais. Foi apontado que essa prática gerava incômodo 
e tensão nas mulheres pela necessidade de permanecerem imóveis.

[...] na época do Mateus, eu não levantava da cama pra nada, colocaram um monte de aparelho em mim, pra ouvir o coração do neném, não podia nem me virar direito, foi horrível! Eu fiquei praticamente aquelas 12 horas ali, parada [parto anterior]. Nesse, a enfermeira perguntava pra mim como eu preferia ficar: em pé, se eu queria sentar, ficar deitada, que eu ficasse do jeito que fosse melhor pra mim. Eu ficava mais deitada, na hora que vinham as contrações mesmo, você não aguenta andar muito. Aí, eu falei pra ela que estava sentindo muita dor; ela recomendou que eu tomasse um banho, foi aí que ele desembestou a querer nascer, foi rapidinho. Falei: se soubesse, tinha tomado banho antes [...] [parto atual] (E2).

Contudo, algumas participantes trouxeram "percepções negativas", apontando para as seguintes questões: preferência em ficar deitada, risco de o bebê nascer durante a movimentação e dificuldade para fazer força na posição vertical.

Apesar de um grupo de mulheres considerar a posição deitada desconfortável e preferir movimentar-se como relatado anteriormente, outras preferiram permanecer deitadas durante as contrações do trabalho de parto, associando a isso às diferenças de cada organismo, que responde diferentemente para cada mulher.

[...] eu sempre vou para a cama, que já está pertinho de nascer quando eu vou pro hospital. E antes de ir pro hospital, fico deitada, eu não gosto de andar, acho que incomoda mais, eu prefiro ficar deitada [...] [parto atual] (E13).

[...] depende de cada organismo, de cada pessoa, como a outra moça que tinha chegado na noite anterior e até aquela hora ela não tinha dor. No meu caso, eu prefiro ficar deitada esperando [...] [parto atual] (E21).

O medo de o bebê nascer durante a deambulação também foi citado como um fator determinante para que permanecessem deitadas e, mesmo recebendo orientação de um profissional, a mulher se recusou a caminhar.

[...] no dela, logo comecei a sentir as contrações e logo ela já estava nascendo; então é um risco muito grande você ir ao banheiro, de ficar andando e acabar nascendo. Na hora que estava com dor, a enfermeira madava eu andar, mas fiquei deitada, não senti vontade de andar. Ai, na hora da dor, você não sabe o que quer fazer [...] [parto atual] (E19).

[...] no outro, eu fiquei deitada o tempo todo na sala de pré-parto [parto anterior] e desse também. Olha, se dissessem pra mim na hora, você pode andar, eu não ia andar, porque ia ficar com medo de andar, e sei lá, de repente, nascer [...] [parto atual] (E3).

Além da manifestação de medo citada, o fato de estar em posição vertical (em pé ou sentada) foi visto como uma dificuldade a mais para se fazer força por ocasião das contrações. A posição horizontal foi vista como facilitadora para se fazer força e sem risco de o bebê cair no chão.

[...] não sei, quando a gente está em pé, vem contração, é pior, a gente está sentada, vem do mesmo jeito, então eu prefiria deitada logo, porque quando vinha a dor mesmo, é melhor a gente está deitada do que em pé; é perigoso, e se o neném estiver nascendo e a gente em pé? Prefiro deitada, quando vinha contração, você punha mais força, deitada mesmo, com segurança. Em pé, como que você bota força? [...] [parto atual] (E28).

A análise das narrativas junto com a observação no campo de pesquisa indicam mudança positiva na assistência prestada às mulheres no pré-parto, pois já se adota a movimentação como uma estratégia para evolução do trabalho de parto. Em experiências de parto anteriores na instituição, as mulheres raramente se movimentavam durante o trabalho de parto, mesmo aquelas que sentiam a necessidade de andar eram impedidas de fazê-lo. Outro ponto importante levantado foi em relação à autonomia das mulheres, que não sentiram necessidade de se movimentar e foram respeitadas em relação à suas preferências.

\section{Alimentação e ingestão de líquidos durante o trabalho de parto}

Da mesma forma que no item anterior, a possibilidade de ingestão de líquidos durante o trabalho de parto foi percebida pelas mulheres de maneira tanto positiva quanto negativa. As entrevistadas que "aceitaram algum tipo de alimentação e líquidos", durante o trabalho de parto, apontaram aspectos positivos, comparando-se com os partos que tiveram anteriormente, nos quais o jejum era indicado para todas as mulheres.

[...] da outra vez, eu fiquei com fome, não deram nem água [parto anterior]! Dessa, me deram sopa. O chá da tarde eu já não quis mais, porque já estava doendo muito e a água eles deixaram tomar à vontade, foi bom [...] [parto atual] (E1).

[...] no meu caso, tinha só tomado café na minha casa, então, quando foi à noite, pedi qualquer coisa, nem que seja água, estava morrendo de fome. Me deram chá, bolacha e chocolate. Foi bom, porque eu estava morrendo de fome [parto atual]. Na época do meu outro filho, fiquei em jejum [...] [parto anterior] (E30). 
A disponibilização de chocolate em barra também foi citada como uma alternativa, quando a mulher não conseguiu ingerir outros alimentos, além de ter tido um resultado positivo nesse caso.

[...] do primeiro, aos nove meses, eu vomitei, cheguei aqui, vomitei, aí, ainda bem que eu não estava com fome, mas elas me deram chocolate e falaram: olha, você tem que comer que está com a pressão baixa, aí me deram chocolate antes da sala do parto, e eu melhorei [...] [parto atual] (E28).

A mudança referente à oferta de alimentos durante o trabalho de parto foi percebida positivamente e houve a constatação que a ingestão de alimentos, naquele momento, além de não causar nenhum transtorno durante o parto, propiciou às mulheres melhores condições físicas para fazer força no período expulsivo.

[...] dessa agora já teve essa modificação [parto atual], que, das outras vezes, não tinha, não davam água nem alimentação nenhuma, até ter o parto [parto anterior]. Agora não: teve o café, teve o almoço, eles não cortaram nada. Dessa vez, foi diferente. É bom porque eu achei que ia ter uma diferença na hora do parto, mas foi tudo normal, tudo a mesma coisa. É melhor você se alimentar pra ter mais força do que vocêficar enfraquecida [...] [parto atual] (E19).

A melhor condição física da mulher, tanto no parto, como no pós-parto, foi atribuída à alimentação recebida durante o trabalho de parto. $O$ fato de ter ficado em jejum no parto anterior foi apontado como responsável pela fraqueza vivenciada, além da necessidade de maior aporte medicamentoso para sua recuperação física.

Em contrapartida, algumas participantes do estudo "não concordaram em se alimentar e somente aceitaram líquido" durante o trabalho de parto. A razão apontada foi que a ingestão de comida poderia atrapalhar o parto.

[...] eu acho que o líquido sim, porque a gente sente muita sede; agora a alimentação já não acho bom, porque pode atrapalhar no parto; no meu caso, se eu tivesse comido o macarrão que nem a moça do meu lado quis comer, imagina o que não tinha saído na hora que eu tinha tido esse menino. Acho que uma coisa pesada assim já não dá, mas acho que um suco, uma água era sempre bom a gente estar tomando lá [...] [parto atual] (E2).

Um dos fatos de recusarem a alimentação oferecida é devido ao temor de passar mal e vomitar durante o trabalho de parto. Outra questão é ter experiência anterior de parto em que se sentiu enjoada e vomitou durante as contrações. A dor também foi apontada como uma razão para que as mulheres se recusassem a aceitar qualquer alimentação oferecida.

[...] eles perguntaram se eu queria chá com bolachas, mas eu não aceitei [parto atual], porque, das outras duas filhas, na hora das contrações, eu acabei vomitando e estava com o estômago vazio [...] [parto anterior] (E21).

[...] me trouxeram um chá com umas bolachas, mas eu não aguentei comer nada, estava com muita dor, então não aguentei comer [...] [parto atual] (E2).

Frente a esses dois pontos, aceitação ou não de alimentos e líquidos durante o trabalho de parto, emerge a "incompreensão das mulheres". Essa, em parte, devido à falta de explicação, pelos profissionais, sobre tais questões.

[...] nessa parte aí eu não entendo muito. Às vezes, eles não dão porque diz que a gente pode vomitar na hora do parto; foi isso que o doutor falou pra mim. Eu falei: doutor, eu quero água e ele falou: não, que você já vai ter o neném e pode, na hora, querer vomitar; foi isso que ele falou pra mim, mas não explicou nada [...] [parto anterior] (E15).

[...] como eu não entendo muito, não posso falar, acho que pode prejudicar alguma coisa, pra não deixarem comer. Porque as mulheres que estavam certo do parto normal, eles davam, no meu caso, como estava duvidoso, então podia prejudicar em alguma coisa. Mas não entendo quando pode e quando não pode comer [...] [parto atual] (E6).

Conforme os relatos, a justificativa alegada pelos profissionais para o jejum no momento do trabalho de parto foi a prevenção contra náuseas e vômitos, sendo este argumento aceito pelas mulheres, porém sem possibilidade de contestação. Há uma aceitação plena por parte das mulheres quanto às orientações recebidas durante a assistência, não havendo questionamentos em relação às condutas e intervenções realizadas. Porém, é importante frisar, cabe o direito a essas mulheres de participarem das decisões na sua assistência, e isso somente ocorrerá, de forma plena e consciente, quando as relações entre os profissionais de saúde e os pacientes se processarem de forma horizontal, com troca de informações entre os dois lados e não apenas um lado (dos profissionais) falando e decidindo.

\section{DISCUSSÃO}

Nos resultados apresentados neste artigo, comparando-se as duas experiências de parto das mulheres no HU/USP, percebeu-se uma mudança na postura dos profissionais em relação à movimen- 
tação das parturientes. Atualmente, não somente é dada liberdade para que a mulher se movimente, como também é incentivado que ela o faça, visando maior efetividade das contrações e melhor evolução do trabalho de parto. A autonomia das parturientes para a movimentação no pré-parto também foi respeitada, pois aquelas que não sentiram vontade de andar puderam permanecer no leito.

Essa autonomia da mulher na escolha da posição e da movimentação durante o trabalho de parto é recomendada no Guia de Atenção Humanizada ao Parto do Ministério da Saúde ${ }^{10}$ e, no geral, o que se percebe é que há uma alternância espontânea nas posições escolhidas pelas mulheres. ${ }^{4}$ A OMS recomenda que essa busca por posições agradáveis seja estimulada pelos profissionais. ${ }^{1}$

Porém, antes da disseminação de tais recomendações, no Centro Obstétrico do HU/USP a prática predominante era a monitorização contínua das mulheres no trabalho de parto, pela utilização de modernos monitores fetais e pelo modelo assistencial pautado em protocolos. Atualmente, já ocorre maior flexibilização na monitorização eletrônica das parturientes, isso em decorrência de estudos que apontam para os benefícios da movimentação no trabalho de parto, ${ }^{3}$ além da experiência de alguns elementos da equipe que atuam em outras instituições nas quais tal prática da movimentação traz resultados positivos.

Incentivando a assistência baseada nas evidências, no Centro Obstétrico do HU/USP, após reforma, foi afixado, em todas as salas de pré-partos, um quadro elaborado pela Japan International Cooperation Agency (JICA) que, através de figuras ilustrativas, demonstra as posições que favorecem o alívio da dor no trabalho de parto e traz orientações quanto à massagem de conforto na região lombar e à deambulação. ${ }^{11}$

Com a deambulação, uma das possibilidades para o alívio da dor no trabalho de parto, é o banho de ducha com água morna. Essa possibilidade é oferecida às mulheres no pré-parto, pois proporciona uma sensação de relaxamento físico e mental, o que, no caso das parturientes, traz efeitos benéficos para a evolução do trabalho de parto.

Sobre esse tema, em um estudo conduzido no HU/USP, no qual se investigou a relação do banho de aspersão com o alívio à dor do trabalho de parto, $79 \%$ das parturientes de uma amostra experimental de 20 mulheres relataram que o banho trouxe relaxamento e conforto físico, naquele momento. Além da melhora da sensação de dor, as mulheres também perceberam que houve aumento das contrações e aceleração do trabalho de parto. Com a divulgação dos resultados dessa pesquisa, consensuou-se, entre o grupo de enfermeiras do Centro Obstétrico do HU/USP, que a indicação do banho durante o trabalho de parto era uma estratégia a ser utilizada de forma sistemática para o alívio da dor, antes de se iniciarem as intervenções farmacológicas. ${ }^{12}$

Pelos resultados apresentados neste artigo, percebe-se um indicativo que tal prática está incorporada na referida instituição, pois mesmo as mulheres que preferiram ficar deitadas, foram estimuladas a irem ao banho.

Nossos resultados corroboram uma pesquisa clínica experimental, controlada e randomizada, realizada em um Centro de Parto Normal, na qual as mulheres do grupo experimental atribuíram valores menores nos índices para a dor do trabalho de parto com o banho de imersão, não havendo diferenças estatísticas em relação à duração do trabalho de parto, comparando-se com o grupo controle. Dessa forma, o banho de imersão mostra-se como uma estratégia eficaz, como método não farmacológico para alívio da dor. ${ }^{13}$

Em um outro estudo, do tipo ensaio clínico controlado prospectivo, realizado também na referida instituição, foi constatado que a ação na estrutura osteomuscular facilitou a progressão da fase ativa e que a mobilidade pélvica promoveu a evolução da dilatação. ${ }^{14}$ Outra pesquisa demonstrou que as mulheres que tiveram orientações de um profissional, em relação à movimentação durante o trabalho de parto, sentiram-se mais seguras para se movimentarem e fizeram uso consciente do corpo, fato que favoreceu o parto vaginal. ${ }^{15}$

Em relação à categoria que trata a ingestão de alimentos e líquidos, as mulheres também se posicionaram com percepções positivas e negativas. As entrevistadas, que aceitaram algum tipo de alimentação, afirmaram que tiveram mais força durante o trabalho de parto. Já as que não concordaram em se alimentar, justificaram-se pelo fato de temerem problemas durante o trabalho de parto. A aceitação de líquidos foi unânime.

Contudo, apesar de as mulheres se posicionarem a favor ou contra essa questão da alimentação, nas narrativas percebe-se a falta de entendimento sobre o assunto. Elas não entendem os motivos da necessidade ou não do jejum e os profissionais não se detêm a dar explicações.

No Centro Obstétrico do HU/USP, a oferta de líquidos e alimentos às parturientes teve início em 2003, apoiada pelas chefias locais - médica e 
de enfermagem. Antes dessa iniciativa, a regra geral era o jejum para todas as mulheres que estivessem em trabalho de parto e as raras exceções eram aquelas mulheres com quadros de inibição de trabalho de parto prematuro ou observações por abortamento e hiperemese gravídica. Essa norma era apoiada em um modelo tecnocrático de assistência, no qual o processo de parto era visto como um evento "fisiologicamente patológico" que, a qualquer momento, poderia necessitar de intervenção cirúrgica.

Porém, no caso de gestantes, o jejum não atinge o objetivo de manter o estômago vazio, pois haverá sempre um resíduo mínimo de $100 \mathrm{ml}$ no volume gástrico, independente do período da última refeição. O que indica, como preferível ao jejum, a ingestão de alimentos pobres em resíduos e de líquidos de sabor agradável a intervalos frequentes. ${ }^{5}$ Segundo a OMS, a adoção de dietas brandas, para repor as fontes de energia requeridas no trabalho de parto, previne a desidratação e a cetose, garantindo o bem-estar da mulher. ${ }^{1}$ Portanto, a oferta de líquidos e alimentos leves por via oral à parturiente, respeitando o seu desejo, além de não interferir no desenvolvimento do trabalho de parto e do parto, pode ser benéfica. ${ }^{16}$

Baseando-se nas evidências dos efeitos negativos da restrição alimentar durante o trabalho de parto, as equipes de obstetras e enfermeiras do Centro Obstétrico do HU/USP propuseram a oferta de alimentos leves e líquidos para as parturientes, iniciativa essa que gerou conflitos junto à equipe de anestesistas, naquela ocasião, relutantes em aceitar essa mudança. Além disso, havia a questão operacional do fornecimento dos alimentos, do acondicionamento na unidade e do estabelecimento de critérios para a oferta.

Nesse sentido, a colaboração do Serviço de Nutrição e Dietética do hospital foi essencial para que essa iniciativa tivesse sucesso. No início, houve a necessidade de ajustes, tanto em relação à quantidade de alimentos quanto ao tipo fornecido. Dentro das possibilidades da instituição, a alimentação fornecida rotineiramente às parturientes segue os critérios estabelecidos pelas equipes. A normatização final a que se chegou foi que mulheres, em fase latente ou no início do trabalho de parto, receberiam uma dieta considerada geral branda, de fácil digestão, após avaliação do seu quadro. Para aquelas em fase ativa do trabalho de parto, a oferta seria de uma dieta líquida composta basicamente de sopa e gelatina e/ou uma barra de chocolate, pelo seu valor energético e pela fa- cilidade na digestão. Em todos os períodos, ainda há a possibilidade de se oferecer à parturiente chá com bolachas ou chocolate em barra.

Por outro lado, considerando que a experiência de se alimentar durante o trabalho de parto é uma prática recente no nosso meio, há ainda insegurança nas mulheres de que isso possa trazer alguma complicação. A incorporação das justificativas dadas pelos profissionais à necessidade de jejum, em experiências anteriores, é, também, um dos fatores que levam as mulheres a recusarem a alimentação oferecida.

Além disso, as características individuais das mulheres também devem ser respeitadas, pois pessoas reagem diferentemente em cada situação: nervosismo e dor podem trazer inapetência ou desencadear acessos de fome. ${ }^{7}$

\section{CONSIDERAÇÕES FINAIS}

As mulheres participantes deste estudo tiveram opiniões divergentes sobre deambulação e alimentação e ingestão de líquidos durante o trabalho de parto e isso deve ser levado em consideração ao se estabeleceram normas e rotinas dentro de uma instituição que visa prestar assistência de qualidade à mulher. As mulheres constroem, a partir de suas experiências, saberes que vão embasar as formas de reagir às situações específicas, determinando, no contexto da saúde, a adoção ou não de determinadas recomendações profissionais.

Várias estratégias, como a deambulação, o banho, a oferta de alimentos e líquidos durante o trabalho de parto, podem contribuir para o alívio da dor e para uma experiência significativa da mulher. Contudo, os resultados desse estudo sugerem que é crucial levar em consideração a individualidade e a autonomia de escolha das mulheres, premissas básicas quando se busca a assistência humanizada. Além disso, o respeito pela perspectiva da mulher, associada à experiência profissional e às evidências científicas são o fundamento para a construção de assistência à saude com qualidade.

\section{REFERÊNCIAS}

1. Organização Mundial de Saúde. Maternidade segura. assistência ao parto normal: um guia prático. Genebra (CH): OMS; 1996.

2. Barratt A. Evidence based medicine and shared decision making: the challenge of getting both evidence and preferences into health care. Patient Educ Couns. 2008 Dec; 73(3):407-12. 
3. Miquelutti MA, Cecatti JG, Morais SS, Makuch MY. The vertical position during labor: pain and satisfaction. Rev Bras Saude Mater Infant. 2009 OutDec; 9(4):393-8.

4. Miquelutti MA, Cecatti JG, Makuch MY. Upright position during the first stage of labor: a randomized controlled trial. Acta Obstet Gynecol Scand. 2007; 86:553-8.

5. Mouta RJO, Progianti JM. Estratégias de luta das enfermeiras da Maternidade Leila Diniz para implantação de um modelo humanizado de assistência ao parto. Texto Contexto Enferm. 2009 Out-Dez; 18(4):731-40.

6. Enkin M, Keirse MJNC, Neilson J, Crowther C, Duley L, Hodnett E, et al. Guia para atenção efetiva na gravidez e no parto. $3^{\mathrm{a}}$ ed. Rio de Janeiro (RJ): Guanabara Koogan; 2005.

7. Diniz CSG. Humanização da assistência ao parto no Brasil: os muitos sentidos de um movimento. Ciênc Saúde Coletiva. 2005 Jul-Set; 10(3):627-37.

8. Wei CY. Ações humanizadoras na assistência ao parto: experiência e percepção de um grupo de mulheres em um hospital-escola [dissertação]. São Paulo (SP): Universidade de São Paulo, Programa de Pós-Graduação em Enfermagem; 2007.

9. Minayo MCS. O desafio do conhecimento: pesquisa qualitativa em saúde. $9^{a}$ ed. São Paulo (SP): HUCITEC; 2006.
10. Ministério da Saúde (BR), Conselho Nacional de Saúde. Resolução No 196 de 10 de outubro de 1996: diretrizes e normas regulamentadoras de pesquisa envolvendo seres humanos. Brasília (DF): MS; 1996.

11. Japan International Cooperation Agency. Manual do parto humanizado. Fortaleza (CE): JICA; 2000.

12. Ochiai AM. O banho de chuveiro como medida de alívio da dor no trabalho de parto [dissertação]. São Paulo (SP): Universidade de São Paulo, Programa de Pós-Graduação em Enfermagem; 2000.

13. Silva FMB, Oliveira SMJV. O efeito do banho de imersão sobre a dor e a duração do trabalho de parto. Rev Esc Enferm USP. 2006 Mar; 40(1):57-63.

14. Bio ER, Bittar RE, Zugaib M. Influência da mobilidade materna na duração da fase ativa do trabalho de parto. Rev Bras Ginecol Obstet. 2006; 28(11):671-79.

15. Carraro TL, Knobel R, Frello AT, Gregório VRP, Grudtner DI, Radunz V et al. O papel da equipe de saúde no cuidado e conforto no trabalho de parto e parto: opinião de puerpéras. Texto Contexto Enferm. 2008 Jul-Set; 17(3):502-9.

16. Torcata A, Gualda DMR. Práticas comprovadamente úteis e que devem ser estimuladas durante o trabalho de parto e parto, que estão sendo realizadas por enfermeiras obstétricas: revisão da literatura. Rev Tec-cientif Enf. 2010; 25(8):152-59.
Correspondência: Dulce Maria Rosa Gualda

Universidade de São Paulo. Escola de Enfermagem

Departamento de Enfermagem Materno Infantil e Psiquiátrica

Av. Dr. Enéas de Carvalho Aguiar, 419

05403-000 - Cerqueira Cesar, São Paulo, SP, Brasil

E-mail: drgualda@usp.br
Recebido: 27 de agosto de 2010

Aprovação: 10 de outubro de 2011 